\title{
OS GÊNEROS TEXTUAIS NA FORMAÇÃO INICIAL DE PROFESSORES DE QUÍMICA
}

\author{
Franciellen Rodrigues da Silva Costa ${ }^{1}$ \\ Sérgio Camargo²
}

\begin{abstract}
RESUMO
O presente trabalho trata-se de resultados parciais de uma pesquisa de mestrado, a qual teve por objetivo investigar que contribuições são percebidas por futuros professores de Química a partir da utilização de diferentes gêneros textuais durante um processo formativo. O recorte reúne dados constituídos por meio de observações das reuniões semanais, relatórios semestrais e de entrevistas semiestruturadas com os bolsistas do subprojeto de Química do Programa Institucional de Bolsa de Iniciação à Docência (PIBID) de uma instituição federal de ensino superior do estado do Paraná. Utilizou-se como metodologia de análise elementos da Análise de Conteúdo, sendo as categorias definidas, a priori, mediante os referenciais teóricos em torno dos gêneros textuais. Os resultados revelaram que a utilização de diferentes materiais didáticos permitiu aos licenciandos aperfeiçoarem suas habilidades de leitura e escrita, sinalizando a importância dessas ferramentas na formação de professores. Entre estas constatações, pode-se ressaltar: a ampliação de vocabulário, o aperfeiçoamento na interpretação, a síntese de textos, bem como o incentivo à prática de leitura.
\end{abstract}

Palavras-chave: PIBID. Gêneros Textuais. Ensino de Química.

\section{TEXTUAL GENRES IN THE INITIAL FORMATION OF CHEMISTRY TEACHERS}

\begin{abstract}
The present work is partial results of a master's research, which aimed to investigate what contributions are perceived by future chemistry teachers from the use of different textual genres during a formative process. The section gathers data consisting of observations of weekly meetings, semi-annual reports and semistructured interviews with the scholarship holders of the Chemistry subproject of the
\end{abstract}

\footnotetext{
1 Doutora em Ensino de Ciências e Matemática pela Universidade Estadual de Maringá (UEM). Professora auxiliar da Universidade Estadual de Feira de Santana (UEFS) - Brasil. Membro do Grupo de Estudos e Pesquisa: Tendências e Perspectivas do Ensino de Ciências GETEPEC - UEL e do Grupo de Pesquisa Processos Formativos e Linguagens na Educação em Ciências da Natureza - UFPR. Orcid iD: https://orcid.org/0000-0003-3381-1179. E-mail: franciellencostaa@gmail.com

2 Doutor em Educação em Ciências pela Universidade Estadual Paulista "Júlio de Mesquita Filho" Faculdade de Ciências/Campus de Bauru - Brasil. Docente Associado da Universidade Federal do Paraná (UFPR) / Setor de Educação/Depto. de Teoria e Prática de Ensino. Docente do Programa de Pós-Graduação Educação: Teoria e Prática de Ensino. Docente e Coordenador do Programa de Pós-Graduação em Educação em Ciências e em Matemática. Líder do Grupo de Pesquisa em Ensino e Aprendizagem de Ciências e Matemática - UFPR. Orcid iD: https://orcid.org/0000-0001-8766-5424. E-mail: sl.camargo@gmail.com
} 
Institutional Program of Teaching Initiation Scholarship (PIBID) of a federal institution of higher education in the state of Paraná. The methodology of analysis was elements of Content Analysis, and the categories were defined, a priori, through the theoretical references around textual genres. The results revealed that the use of different teaching materials allowed undergraduates to improve their reading and writing skills, signaling the importance of these tools in teacher education. Among these findings, it can be highlighted: the expansion of vocabulary, the improvement in interpretation, the synthesis of texts, as well as the incentive to practice reading.

Keywords: PIBID. Textual Genres. Teaching of Chemistry.

\section{GÉNEROS TEXTUALES EN LA FORMACIÓN INICIAL DE PROFESORES DE QUÍMICA}

\section{RESUMEN}

El presente trabajo es el resultado parcial de una investigación de maestría, que tuvo como objetivo investigar qué contribuciones son percibidas por los futuros profesores de química a partir del uso de diferentes géneros textuales durante un proceso formativo. La sección reúne datos consistentes en observaciones de reuniones semanales, informes semestrales y entrevistas semiestructuradas con los becarios del subproyecto Química del Programa Institucional de Becas de Iniciación Docente (PIBID) de una institución federal de educación superior en el estado de Paraná. La metodología de análisis fue elementos de Análisis de Contenido, y las categorías fueron definidas, a priori, a través de las referencias teóricas en torno a géneros textuales. Los resultados revelaron que el uso de diferentes materiales didácticos permitió a los estudiantes de pregrado mejorar sus habilidades de lectura y escritura, señalando la importancia de estas herramientas en la formación docente. Entre estos hallazgos, se pueden destacar: la expansión del vocabulario, la mejora en la interpretación, la síntesis de textos, así como el incentivo para practicar la lectura.

Palabras clave: PIBID. Géneros Textuales. Enseñanza de la Química.

\section{INTRODUÇÃO}

A maioria das metodologias tradicionais utilizadas para a compreensão dos conhecimentos químicos baseia-se na memorização de conceitos químicos e reprodução de conceitos matemáticos, contribuindo para a existência da falta de importância da linguagem e da escrita no ensino de Química. Isto ocorre, segundo Queiroz (2001, p. 1), por se tratar de um campo científico, potencialmente quantitativo, no qual os currículos dos cursos ainda "enfatizam o desenvolvimento de habilidades quantitativas, como a efetuação de cálculos e resolução de problemas, em prejuízo do desenvolvimento de habilidades qualitativas, como a escrita".

Atualmente, poucos estudantes formados nos cursos de Licenciaturas na área de Ciências Exatas, inclusive no curso de Química, têm a facilidade 
em redigir um texto de forma coerente, expressiva e com um bom vocabulário. Este fato se deve, entre outras coisas, às escassas situações formativas que envolvam os licenciandos ao estímulo e a descoberta pelo prazer de ler.

A falta de leitura não limita o déficit apenas na escrita, mas traz sérios problemas na apreensão das ideias que envolvem os conceitos científicos, visto que as diferentes linguagens perpassam todos os campos de conhecimento. Há a necessidade da inserção de textos que despertem a curiosidade e o interesse pelo ato de ler, de modo que a interpretação dos fenômenos e conteúdos químicos seja auxiliada, minimizando assim, a problemática da dificuldade de compreensão dos conceitos químicos (ALMEIDA, 1998). Com isso, o currículo de Química deve estar também direcionado às habilidades e competências indicadas na BNCC, as quais envolvem diferentes tipos de linguagens, na tentativa de melhorar a interpretação de textos e as diversas formas de expressar e comunicar seus conhecimentos (BRASIL, 2017).

Autores como Teixeira Júnior e Silva (2007, p. 1) apontam que a leitura deve ser assumida principalmente nos cursos de Licenciaturas, "tendo em vista o desenvolvimento do professor leitor, bem como a constituição de mediadores do ato de ler, que engendram e constroem sentidos e práticas de leitura". Além disso, a importância de se integrar a leitura no ensino de Química, propicia o desenvolvimento de outras habilidades como a comunicação, a análise crítica e a argumentação (FRANCISCO JUNIOR, 2010).

A falta do uso de gêneros textuais pelos professores, em suas salas de aula no Ensino Superior, muitas das vezes, também está associada à ausência do encantamento deles pelos gêneros textuais durante suas trajetórias na formação acadêmica. Pois, segundo Cunha (1986), não se pode transmitir uma emoção ou um gosto, daquilo que não se sente. Se o professor não se sensibilizar pela leitura, dificilmente conseguirá emocionar seus alunos, e contribuir para que eles façam o uso dos mesmos em suas futuras práticas pedagógicas (CUNHA, 1986). 
Desse modo, o incentivo para outras leituras, ou seja, diferentes gêneros textuais, também permite formar leitores capacitados para "produzir textos coerentes, coesos e adequados quanto à ortografia e à situação de comunicação" (BASTOS, 2008, p. 2). Sendo que, esta deve ser uma dentre as outras preocupações de todos os educadores químicos enquanto formadores nos cursos de Licenciaturas.

Apesar das considerações supracitadas, não encontramos muitas publicações referentes à utilização de gêneros textuais nos cursos de Licenciatura em Química. O que nos leva a concluir que esse é um tema ainda pouco explorado nesta área do conhecimento, tornando o campo de pesquisa amplo e bastante interessante do ponto de vista da formação de professores de Química, por buscar enxergar as potencialidades da utilização de gêneros textuais não só na Educação Básica, mas também no Ensino Superior.

Nesse sentido, promover a inserção da leitura e da escrita em ações formativas durante os cursos de licenciatura pode ser um pequeno passo para incentivar os futuros professores para a apreciação dos diferentes tipos de gêneros textuais e utilização desses recursos em sala de aula na Educação Básica. Com isso, buscamos apresentar nesta investigação, a inserção de diferentes tipos de textos na formação inicial de professores de Química no âmbito do PIBID, com o objetivo de identificar que contribuições são percebidas pelos licenciandos durante esse processo formativo.

\section{LER E ESCREVER NO ENSINO DE QUÍMICA}

Nas últimas décadas, a proporção de leitores entre jovens tem diminuído, em contrapartida este fato causa estranheza ao saber que se aumentaram os investimentos para o acesso à escolarização. A justificativa para tal situação deve estar associada aos gostos deles, visto que os jovens têm preferido o cinema e a televisão, pela rapidez e a facilidade da informação, ou a preferência pela música e pelo esporte, que são prazeres compartilhados (PETIT, 2008). Desse modo, consideramos o livro, entre outros textos, perdidos nos espaços e longe dos gostos de nossos estudantes. 
O estudante em muitas das vezes "lê apenas o que julga necessário para conseguir nota, ou seja, não enxerga benefícios na leitura, percebe-a como algo não prazeroso, chato e enfadonho" (NICHIO, PACífICO, 2020, p.17). Isto pode estar relacionado à dificuldade dos estudantes na compreensão dos próprios textos, em que tais situações criam um distanciamento deles pela leitura, por caracterizá-la como chata e desnecessária.

Com isso, a ausência de leitura no contexto educacional tem se configurado como uma crise de leitura permanente, onde os estudantes em todos os níveis de ensino têm apresentado dificuldades nas interpretações e/ou elaborações de textos. Portanto, os professores também se tornam corresponsáveis desta situação, ao isolar o processo de leitura apenas a uma área do conhecimento e não compreender que este problema é de todos os educadores, até mesmo daqueles das áreas exatas (DEYLLOT, ZANETIC, 2004).

Apesar do ato de ler estar ligado primeiramente à decodificação de símbolos, palavras e frases, não pode se limitar a isso. Segundo Freire (2001, p. 11) a "compreensão crítica do ato de ler, [...] não se esgota na decodificação pura da palavra escrita, mas [...] antecipa e se alonga na inteligência do mundo". A linguagem não pode ser reduzida a uma ferramenta, mas na "construção de nós mesmos enquanto sujeitos falantes", onde a existência é medida pelo peso das palavras ou ausência delas (PETIT, 2008, p.16).

Ler é aprofundar os significados das palavras, admirar a construção literária ou uma construção científica tanto pelo poder explicativo como a elaboração epistemológica (DEYLLOT, ZANETIC, 2004). Ler ainda está além do próprio entendimento das entrelinhas, daquilo que está aparente aos olhos, ou seja, da sensibilidade de olhar os versos e tirar dele a emoção (PETIT, 2008). São estes hábitos, segundo a autora, que remetem os sujeitos para os diversos lugares, tempo e gosto, além de propiciar a imaginação e a criatividade. 
Saber ler também mantém o indivíduo no mercado de consumo, permitindo e incentivando-o a adquirir outros tipos de textos (PETIT, 2008). E esta condição não é imposta ao sujeito, mas construída por ele, diante de sua trajetória formativa de leitor, na medida em que o ato de ler também o propiciará a competência para o desenvolvimento da escrita.

Outra perspectiva, a ser considerada por Dionísio, Pereira e Viseu (2011), deve-se às competências de comunicação, as quais não devem se restringir às aulas de Língua Portuguesa, e sim assumir como objetivo igualmente central das restantes áreas curriculares. Na visão dos autores, ler e escrever são tarefas complexas e devem ser ensinadas, intencionalmente, em todos os níveis de ensino e em todas as disciplinas. O ato de ler e escrever torna-se base para a aprendizagem do conhecimento escolar, pois é, antes de tudo, uma questão de linguagem, sendo uma condição essencial para conhecimento.

Ainda na visão de Dionísio, Pereira e Viseu (2011), os professores das disciplinas destinadas às Ciências da Natureza, muitas das vezes prendem-se apenas a propor estratégias de ensino direcionadas ao desenvolvimento de habilidades quantitativas, como a resolução de problemas, o raciocínio lógico, a memorização de equações matemáticas, a conversão de números, esquecendo-se das habilidades qualitativas referentes à comunicação, interpretação, síntese de textos, entre outros.

Para Flôr (2015), a exigência da ampliação de novas leituras reporta-se também às mudanças propostas para a seleção de ingresso nas universidades. Um exemplo é o caso do ENEM, que enfatiza habilidades e competências ligadas "a uma superação da visão instrumental da linguagem, exigindo que se estabeleçam relações entre textos e saindo do contexto de memorização que se refere às Ciências Exatas" (FLÔR, 2015, p.191).

Diante das potencialidades, a inserção à prática da leitura nos processos formativos pode condicionar o sujeito a sua constituição enquanto apreciador de diferentes textos, contribuindo para o desenvolvimento do seu poder argumentativo. Além disso, tais ações formativas podem promover ao 
sujeito o domínio de vários recursos textuais, a constituição de um repertório de literacia e possíveis formas de desenvolverem estratégias para integrar a leitura e escrita na sala de aula (DIONÍSIO, PEREIRA, VISEU, 2011).

Sem embargo, enfatizamos a conceituação de um gênero textual. Segundo Baltar (2010) eles incluem a diversidade de textos discursivos que circulam pela sociedade. A diversidade de textos ainda abrange a variedade de estudos (GALVÃO, 2006; CASSIANI, NASCIMENTO, 2006; OLIVEIRA, CARVALHO, 2005; FRANCISCO JÚNIOR, 2010) que apontam resultados satisfatórios para o uso destes recursos para o Ensino de Ciências. Além de estudos dedicados à área de Ensino de Química (TEIXEIRA JÚNIOR, SILVA, 2007; ZANON, ALMEIDA, QUEIROZ, 2007; STRACK, LOUGUERCIO, DEL PINO, 2007; MASSI, SANTOS, QUEIROZ, 2008) que investigam a importância da utilização da leitura no processo de formação dentro dos cursos de Licenciatura.

Diante da variedade de estudos, que compreende a multiplicidade de materiais didáticos, entre eles os gêneros textuais, como as Histórias em Quadrinhos, os Poemas, os Livros de Literatura e os Jornais, os professores de Química indicam sentir-se inseguros em utilizá-los em sala de aula (COSTA, SILVA, CAMARGO, 2016). Tal insegurança pode estar associada à falta de conhecimento dos professores sobre as potencialidades didáticas dos recursos, bem como sua falta de apreciação dos textos, pela ausência de práticas de leituras.

Dos diferentes gêneros textuais, o poema, segundo Bastos (2008, p. 3) "é um gênero textual com características próprias que permite através da sua linguagem polissêmica, o desenvolvimento da imaginação, do senso crítico, da expressão oral e escrita e do vocabulário". Sendo que este "pode ser utilizado em sala de aula como uma forma alternativa de se estabelecer ligações entre os conhecimentos das mais variadas disciplinas" (ZANOTTO, STADLER, CARLETTO, 2012, p. 2). Com isso, os trabalhos, de forma interdisciplinar e transdisciplinar, poderiam ser contemplados.

A riqueza de um poema está na possibilidade de o professor apreciar tal gênero, e encontrar nele significados em suas aulas. Um exemplo, para o 
ensino de Ciências, é apontado por Silva (2011) por meio de suas apreciações aos poemas de António Gedeão. Em seu artigo, a autora, apresenta as potencialidades do poema para o Ensino de Química. Deste modo, levar o poema para as aulas de Química é uma maneira de ampliar a visão de mundo para as diferentes formas de conhecimentos e vislumbrar novos saberes.

Apesar das potencialidades, segundo Scheid (2013), entre os gêneros textuais, o poético é o que apresenta maior destaque em relação à dificuldade de utilização pelos professores, por ele ser considerado um gênero textual difícil. Para a autora, isso ocorre devido ao desconhecimento da potencialidade didática que envolve o poema, acarretando o preconceito do uso do material em sala de aula. Esta situação pode ser ampliada a outros gêneros textuais, justificada pelo despreparo ou a falta de conhecimento dos professores para com os diferentes tipos de gêneros textuais em sua formação.

No caso da Literatura no Ensino de Química, estudos como o de Silveira e Zanetic (2017), indicam a interação entre Ciência e Literatura como ferramenta para fazer diferentes leituras a partir de duas perspectivas. Assim, para tais autores, trazer a Ciência de outra maneira, por meio da Literatura, permite confrontar os dois campos antagônicos, na valorização de ambas as áreas do conhecimento, levando os leitores a pensar criticamente nas diversas relações que permeiam entre as linhas do texto.

Desta forma, na opinião de Silveira e Zanetic (2017, p. 92), a Literatura indica ser uma alternativa para uma "formação mais ampla do ponto de vista cultural e a oportunidade de vivenciar diferentes olhares a respeito da realidade". Sendo que o texto promove uma forma de diálogo que resgata a capacidade de reflexão e da imaginação. Neste ponto Silveira (2013) indica existir um consenso entre pesquisadores, sobre a importância da imaginação, uma vez que "a capacidade de imaginar é essencial no processo criativo para ambas as áreas e não restrita somente aos artistas" (SILVEIRA, 2013, p. 32). 
Para Petit (2008), o imaginário não é algo com que se nasce, mas constrói-se e é enriquecido ao longo das experiências, como é o caso das possibilidades vivenciadas pela Literatura. Os textos que mais trabalham com a imaginação do leitor são aqueles que não o aprisiona, mas o apresenta pontes ou formas de construir suas asas (PETIT, 2008). Assim, na visão da autora, quando se pode ampliar os horizontes estreitos e criar as relações diversas, é difícil não aguçar a imaginação dos sujeitos.

Outra potencialidade do material indica que "a literatura pode contribuir para a formação de um cidadão contemporâneo mais humano e comprometido com a vida e o coletivo", na medida em que torna um ser humano mais compreensivo e aberto a outras opiniões (SILVEIRA, 2013, p. 35). O fato de conhecer diversas opiniões, argumentos e perspectivas fazem os indivíduos construírem um repertório de saberes. O que leva a "formação mais crítica, reflexiva e capaz de permitir ao professor a promoção de conexões entre conhecimento científico e as questões que norteiam a realidade social, o cotidiano e a vida das pessoas" (SILVEIRA, 2013, p. 43).

Entre outros gêneros textuais, as Histórias em Quadrinhos (HQs), Vergueiro (2009) indica serem recursos com potencialidades didáticas, na inserção de temáticas, na ilustração de ideia, na problematização e na contextualização de conteúdo. Segundo Luyten (1989), o uso das Histórias em Quadrinhos, além das contribuições próprias da Literatura como a imaginação, possibilita aos leitores a melhora das habilidades de leitura e escrita. Este gênero também é considerado um método capaz de aprimorar o ato de escrever, por conta da necessidade de sintetizar as ideias, para colocar o texto em forma de narração e/ou fala dos personagens dentro dos pequenos espaços destinados aos balões, presentes nas Histórias em Quadrinhos (LUYTEN, 1989).

Outro material também importante é o jornal, no qual, segundo Vosgerau e Pinheiro (2012), está entre os gêneros textuais que se destaca em relação a linguagem mais acessível, com assuntos recentes e atualizados, revelando uma atraente possibilidade de informações contextualizadas em sala de aula. Na visão dos autores, a utilização do recurso proporciona uma 
formação mais crítica, ao permitir que, pelas análises das informações publicadas, as influências políticas, sociais e econômicas sejam reconhecidas em torno das reportagens, de maneira a se posicionar perante informações divulgadas.

Enfim, estes são alguns dos vários materiais didáticos que podem ser inseridos na prática docente. No entanto, muitas vezes, devido à ausência de saberes para a sua utilização, os docentes acabam tendo preconceito com esses materiais, inibindo a sua utilização no Ensino de Química (COSTA, CAMARGO, SILVA, 2018). Dessa forma, um dos meios de romper com estas visões equivocadas é promover o contato dos futuros professores de Ciências/Química com estes recursos durante a sua formação inicial.

A familiarização com estes gêneros textuais permitirá ao professor dispor de um repertório de textos de forma diversificada para sua prática pedagógica. Entretanto, para que isto ocorra, são necessários espaços formativos, capazes de vislumbrar e capacitar para o estudo destes recursos, permitindo o seu contato inicial, e a possibilidade de construir gosto e prazer na apreciação destas leituras.

Apesar das vantagens citadas, a temática que envolve a utilização de gêneros textuais no Ensino de Química ainda é pouco discutida, sendo algumas bem recentes. Assim sendo, quando estas discussões são baseadas na elaboração de novas metodologias para o Ensino Superior nos cursos de licenciaturas, ficam mais escassos os trabalhos que tratam desta temática. Deste modo, a formação de professores deve fornecer condições apropriadas para amenizar a problemática instituída em torno dos cursos de licenciaturas, as quais, segundo Camargo (2004), visa a aplicação de práticas sedimentadas através de pedagogias tradicionais, relegando a formação de leitores crítico-reflexivos, por meio do uso de gêneros textuais.

\section{METODOLOGIA}

O desenvolvimento das atividades de pesquisa ocorreu no âmbito do subprojeto de Química, do Programa Institucional de Bolsa de Iniciação à Docência (PIBID), em uma Instituição Federal de Ensino Superior no ano de 2014. A investigação pautou-se no acompanhamento do processo 
formativo, que se utilizou de diferentes gêneros textuais, em forma de estudo dirigido e elaboração de propostas didáticas, a fim de identificar que contribuições podem ser percebidas por futuros professores durante 0 processo de formação inicial.

As atividades acompanhadas para a construção do corpus desta pesquisa são as seguintes: a) A leitura e as discussões de referenciais teóricos selecionados pela coordenadora do subprojeto; b) A elaboração de seminários para apresentação das potencialidades didáticas dos recursos para o ensino de Ciências/Química; c) Análise crítica de recursos didáticos elaborados por outros subprojetos ou disponíveis ao público em bibliotecas e redes de comunicação; d) Apresentações coordenadas de propostas didáticas elaboradas a partir de diferentes recursos didáticos para o ensino de Química na educação básica; e) Atividades teórico-práticas para discussões das possíveis relações dos conteúdos científicos com outras áreas de conhecimento.

A investigação enquadrou-se em uma Pesquisa Qualitativa do tipo Estudo de Caso em que, segundo Lüdke e André (2013), o pesquisador recorre a uma infinidade de informações, que serão constituídas por diferentes instrumentos e técnicas para a coleta dos dados. As características deste tipo de pesquisa incluem como objetivo: cruzar estas informações "para confirmar ou rejeitar hipóteses, descobrir novos dados, afastar suposições ou levantar hipóteses alternativas" (LÜDKE, ANDRÉ, 2013, p. 22). Por conseguinte, para a constituição dos dados, utilizaram-se diferentes instrumentos e técnicas, sendo eles: as observações das reuniões conjuntamente com a elaboração do diário de bordo e as gravações de áudio; a pesquisa documental dos relatórios semestrais e as entrevistas semiestruturadas com os bolsistas.

As observações ocorreram nos encontros distribuídos ao longo do período destinado as reuniões semanais do PIBID, permitindo as anotações descritivas no diário de bordo das atividades desenvolvidas, além do registro dos sujeitos participantes, as orientações, os encaminhamentos para apresentação dos seminários e as discussões dos bolsistas em torno dos 
diferentes recursos didáticos. Em conjunto com esta técnica utilizaram-se as gravações de áudio e registro de imagens. O objetivo das gravações de áudio, foi registrar as informações para revisar os acontecimentos e esclarecimentos das ações realizadas.

A etapa seguinte consistiu na pesquisa documental, referente à análise dos 16 relatórios semestrais elaborados pelos bolsistas do subprojeto e entregue à coordenadora de área. A pesquisa documental teve como objetivo identificar, nos relatos dos bolsistas, possíveis contribuições percebidas por eles nesse processo formativo, além de utilizar a leitura dos relatórios para a seleção dos sujeitos para a entrevista. Desta forma, nesta etapa da pesquisa documental, foram selecionados 8 sujeitos para a entrevista, mediante suas participações em todas as atividades, tanto nas discussões em reuniões, como na elaboração de propostas didáticas, desenvolvidas para a educação básica. A entrevista semiestruturada constituiu-se na última parte da recolha de dados, por meio de um questionário, a fim de identificar, confirmar e ratificar hipóteses levantadas durante a pesquisa documental.

Os dados foram analisados utilizando a metodologia de Análise de Conteúdo, proposta por Bardin (2011). Neste sentido, algumas etapas foram necessárias para sua realização, sendo elas: a) A pré-análise consistiu na seleção dos materiais para compor o corpus de pesquisa, devido à quantidade de documentos gerados. Já na organização, os documentos foram nomeados, utilizando-se códigos R para Relatório e E para Entrevista, sendo acrescentado o índice numérico estipulado para cada sujeito para manter o anonimato dos mesmos; b) A codificação e unitarização dedicouse à leitura minuciosa dos materiais, com o intuito de selecionar as unidades de significado que contemplassem as possíveis contribuições na utilização dos diferentes recursos didáticos em um processo formativo; c) A categorização baseou-se na operação de classificação das unidades de significados pelas semelhanças em categorias a priori, que foram elaboradas a partir dos referencias teóricos sobre as potencialidades didáticas dos gêneros textuais. As categorias compreenderam as contribuições 
relacionadas à melhoria das habilidades de leitura e escrita, a ampliação de vocabulário, o incentivo à leitura, a síntese de textos e aprimoramento na interpretação e compreensão do texto; d) Por fim, a interpretação dos dados teve a função de atingir uma compreensão mais profunda das mensagens dos sujeitos através da inferência por meio das discussões dos resultados.

Dentro dos procedimentos metodológicos descritos, a pesquisa teve como objetivo analisar que contribuições são percebidas pelos bolsistas no processo formativo, que se utilizou de diferentes gêneros textuais no âmbito do subprojeto de Química, no PIBID. Sendo tais interpretações apresentadas no próximo tópico.

\section{RESULTADOS E DISCUSSÕES}

Nesta investigação, que implica no recorte da pesquisa de Mestrado, serão apresentadas as atividades com os quatro materiais didáticos (Poema, Livro de Divulgação Científica, Histórias em Quadrinhos e Jornal), designados e discutidos durante as reuniões internas no subprojeto de Química. A construção das informações contidas nesta explanação de dados é baseada nos registros em diário de bordo, gravações de áudio e vídeo, bem como a pesquisa documental dos 16 relatórios dos bolsistas.

\section{Atividade com o Poema - Lágrima de Preta}

A proposta de abordagem com 0 poema para $\bigcirc$ Ensino de Ciências/Química aconteceu com a explanação de informações, pela coordenadora, sobre suas experiências com o recurso didático. Em seguida, a coordenadora entregou um poema intitulado Lágrima de Preta de Antonio Gedeão, onde solicitou-se que os participantes fizessem uma primeira leitura, a fim de fazer suas próprias interpretações.

Para auxiliar na argumentação e organização das informações contidas no poema, um roteiro impresso foi disponibilizado entre os licenciandos, para indicar: as potencialidades do material para o ensino de Ciências/Química; os possíveis conhecimentos científicos a serem abordados pelo poema; a possibilidade de uso do poema como roteiro prático para 
aulas experimentais, dentre outras. Para finalizar, gerou-se um debate sobre as implicações do poema para discussões dos conceitos científicos relacionados as questões sociais e étnico-raciais.

\section{Atividade com Livro de Divulgação Científica - Tio Tungstênio}

A proposta da atividade pautou-se na apresentação do recurso didático pela coordenadora, esclarecendo as características da obra e informações sobre autor. Com isso, propôs-se a leitura do livro Tio Tungstênio do autor Oliver Sacks, sendo a leitura da obra dividida em capítulos, para os 16 bolsistas (14 licenciandos e 2 professores supervisores), conforme Quadro 1.

QUADRO 1 - Capítulos do livro Tio Tungstênio distribuídos para apresentação

\begin{tabular}{|c|c|c|c|c|c|}
\hline Cap. & Bolsista & Nome capítulo & Cap. & Bolsista & Nome capítulo \\
\hline 1 & todos & Tio Tungstênio & 13 & L5 & $\begin{array}{c}\text { Rodelinhas de madeira do } \\
\text { Sr. Dalton }\end{array}$ \\
\hline 2 & todos & "37" & 14 & L2 & Linhas de força \\
\hline 3 & todos & Exílio & 15 & L2 & Vida em família \\
\hline 4 & L7 & Um metal ideal & 16 & PS1 & Jardim de Mendeleiev \\
\hline 5 & L10 & Luz para as massas & 17 & L9 & Espectroscópio de bolso \\
\hline 6 & L4 & A terra da estibina & 18 & L3 & Fogo frio \\
\hline 7 & L11 & Recreações químicas & 19 & PS1 & Mamãe \\
\hline 8 & L8 & Fedores e explosões & 20 & PS2 & Raios penetrantes \\
\hline 9 & L6 & Consultas domiciliares & 21 & L14 & O elemento de Madame \\
Curie
\end{tabular}

Fonte: os autores.

A proposta da atividade consistiu na leitura dos três primeiros capítulos por todos os bolsistas e, seguidamente, os participantes que ficaram responsáveis pela leitura dos próximos capítulos apresentaram as principais ideias interpretadas em suas leituras. A apresentação dos capítulos ocorreu em conjunto com a exposição oral das possíveis potencialidades didáticas para a utilização do recurso pedagógico no ensino de Química na educação básica. 
A proposta da abordagem possibilitou conhecer os personagens envolvidos, principalmente Oliver Sacks, personagem principal da história. Neste romance autobiográfico, ele descreve os fatos da infância no contexto familiar, e suas experiências de formação, que contribuíram dentre outras coisas, para sua formação cultural e científica, principalmente em relação aos conhecimentos da área de Química. Todas estas discussões foram conduzidas pela coordenadora do subprojeto de Química, a qual trouxe importantes considerações sobre a obra. Em meio a isso, a intenção de apresentar aos licenciandos um livro com divulgação científica, por meio do seu estudo e análise crítica, contribuiu para os bolsistas reconhecerem as potencialidades para a utilização da Literatura como recurso didático para o ensino de Química.

\section{Atividade com as Histórias em Quadrinhos (HQs)}

O estudo das Histórias em Quadrinhos foi dividido em três encontros. No primeiro encontro, estabeleceu-se a leitura de dois capítulos dos seguintes livros: Como usar as Histórias em Quadrinhos na sala de aula organizado pelos autores Angela Rama e Waldomiro Vergueiro e o livro Quadrinhos na Educação escrito pelos autores Waldomiro Vergueiro e Paulo Ramos. O primeiro capítulo, intitulado Os quadrinhos (oficialmente) na escola: dos PCN ao PNBE, apontou os principais documentos curriculares que indicam as HQS com potencialidades para as linguagens. Em seguida, apresentou-se o capítulo A linguagem dos quadrinhos: uma alfabetização necessária, com uma abordagem mais técnica dos termos para a construção e linguagem das HQs.

No segundo encontro, foi designada a pesquisa de softwares, destinados à elaboração de Histórias em Quadrinhos, com o intuito de propor uma atividade prática para a familiarização com a ferramenta. $O$ resultado da busca possibilitou a apresentação de tutoriais de alguns aplicativos para a construção de HQs, como o Comic Life, o Pixton, o Toondoo e a Hagáqué. A última parte pautou-se na apresentação e análise crítica de Histórias em Quadrinhos disponíveis nos meios de Tecnologias de 
Informação e Comunicação (TIC), direcionadas para trabalhar no Ensino de Ciências na educação básica.

No terceiro encontro, houve as discussões baseadas na leitura do capítulo "Mangás em sala de aula" da obra "Quadrinhos na Educação". Além das discussões próprias do texto, apresentou-se um recurso didático em forma de mangá, sendo este intitulado de Sigma Pi, produzido pela acadêmica Adriana Yumi Iwata da Universidade Federal de São Carlos (UFSCAR). O recurso aborda os conceitos de Química, com uma linguagem mais acessível aos jovens, dentro de uma história que lida com situações do contexto escolar, pela participação dos alunos em um clube de Química como parte de suas atividades extracurriculares.

A proposta das atividades baseada no estudo das Histórias em Quadrinhos (HQs), conforme a Figura 1, consistiv em apresentar este gênero textual aos bolsistas como um possível recurso para situações de ensino. Para isso, houve a necessidade de vários encontros com estudos voltados a alfabetização científica sobre suas linguagens, o conhecimento e reconhecimento da diversidade de softwares para a elaboração dos materiais, bem como a análise crítica de recursos pré-existentes.

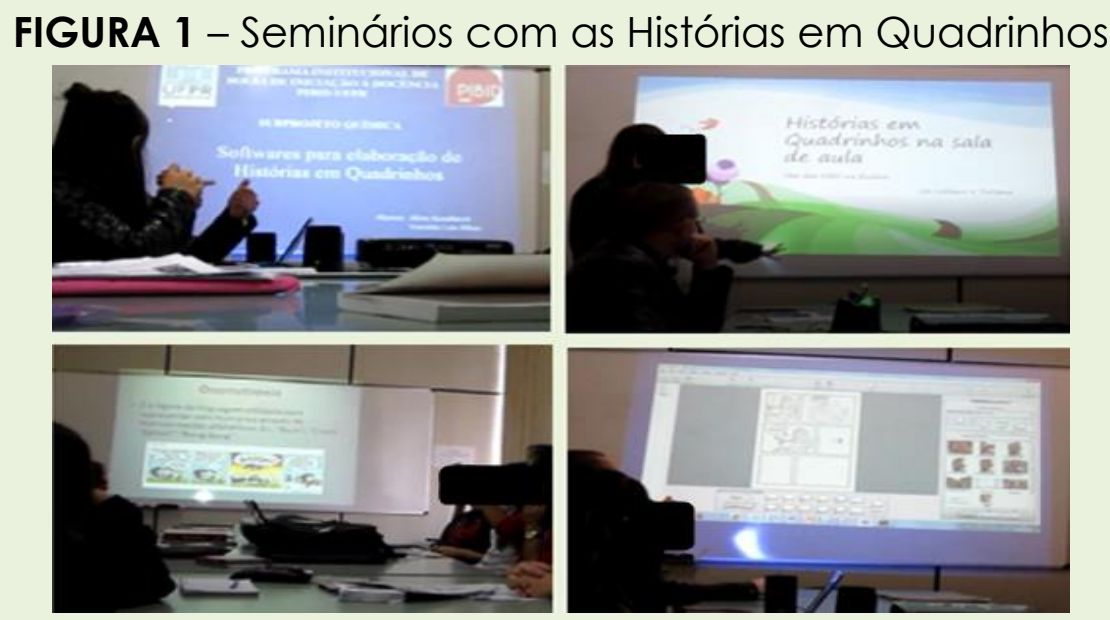

Fonte: os autores.

\section{Atividade com o Jornal}

A atividade iniciou-se pela leitura de dois referenciais teóricos, intitulados de: O uso do jornal impresso na educação básica: resultado de uma década de pesquisa no Brasil e o capítulo do livro Por que o Jornal na 
escola do livro Como usar o Jornal em sala de aula da autora Maria Alice Faria. A partir da leitura dos textos, houve a seleção de uma reportagem de um jornal impresso ou digital, a qual poderia ser usada para uma abordagem durante as aulas de Química na educação básica.

No próximo encontro, os licenciandos, sentados em círculos, receberam um roteiro para a identificação de informações contidas nos jornais. Entre as indicações apresentadas no roteiro, destacam-se: o nome do jornal; a autoria e data da publicação; o título e subtítulo da reportagem; os recursos gráficos; a temática predominante da reportagem e, por fim, classificar a reportagem em relação a uma área de conhecimento. Esta proposta buscou instrumentalizar os licenciandos a conhecer quais são as informações contidas dentro de uma reportagem.

Em seguida, como parte da proposta solicitou-se a cada bolsista que expusesse a sua justificativa para a escolha da reportagem ao restante do grupo. Neste momento, evidenciaram quais as potencialidades de usar o jornal como material didático nas aulas de Química, com ênfase em trabalhar com informações atuais de forma a instigar 0 interesse dos estudantes.

\section{Contribuições formativas/potencialidades didáticas}

A primeira contribuição para o uso dos diferentes gêneros textuais, coexiste nas habilidades de leitura e escrita, a partir das próprias características dos materiais didáticos utilizados. A própria especificidade dos textos possibilitou as suas articulações na proposição de atividades no ensino de Química, tanto para o aprendizado de conceitos científicos, quanto para a importância de abranger as diferentes linguagens, instituídas pelas próprias diretrizes curriculares da educação.

Entre os recursos didáticos dedicados ao estudo dirigido nas reuniões do subprojeto no PIBID, o poema é citado entre os entrevistados, como um instrumento que contribuiu para desenvolver no sujeito-leitor, a capacidade de interpretação e a ampliação de vocabulário. Além disso, o recurso age como uma ferramenta capaz de desenvolver a criatividade dos licenciados, 
até mesmo pela produção de novos poemas, a partir das temáticas e os conteúdos a serem trabalhados em sala de aula.

No caso das habilidades de leitura e escrita, tais como a interpretação, as contribuições são evidenciadas pelo trecho "Eu consegui melhorar a interpretação, principalmente pelo uso do poema, ao conseguir esclarecer informações contidas no texto, de forma a captar a mensagem que está sendo transmitida" (El). A indicação de melhora na interpretação também pode ser vista, no trecho da fala, "Eu lia o poema por ler, eu não conseguia compreender [...] Eu tinha muita dificuldade de interpretação, e com o tempo melhorou muito esta questão da interpretação com a leitura dos poemas para atividades do PIBID" (E7).

Para os entrevistados, o fato de precisar buscar informações para a compreensão das situações não explícitas no poema age como uma ferramenta de estímulo para a melhoraria da sua interpretação. Isto ocorre pelas especificidades do texto poético: sua estrutura e a composição dos versos que requerem do indivíduo uma leitura atenta, que prioriza, além da decodificação de palavras, concentração e sensibilidade para entender suas mensagens implícitas, condicionando o sujeito a aprimorar as suas habilidades de interpretação.

Em relação a melhora de vocabulário, a fala de E3 indica que "[...] há poemas que além de levar o conteúdo químico para sala de aula, também pode trabalhar questões como interpretação, questões da própria ortografia, o conhecimento de novas palavras, justamente por ter uma linguagem mais rebuscada" (E3). Os dados mostraram que os leitores interessados em se apropriar da leitura deste recurso colherão frutos pela sua apreciação. Uma delas está no destaque à ampliação de vocabulário, pelo conhecimento de novas palavras, pela utilização de termos rebuscados, de vocábulos provenientes de contextos regionais específicos, de expressões utilizadas em outras áreas do conhecimento, dentre outros, contribuindo para que a leitura do sujeito congregue maior repertório de vocabulário.

Outra potencialidade evidenciada pelo uso do poema trata-se da característica do gênero textual para a proposição de um ensino 
interdisciplinar. Um exemplo citado na fala E2 "[...] comecei a ver discussões para área de Biologia e Química em um mesmo poema" ou na fala El "[...] é incrivel ler um poema de ver que muitos conceitos não se explicam apenas por uma área". Desta forma, tornar-se um leitor de um poema é abrir a mente para passear em diferentes destinos e lugares, são textos ricos em informações, que não fragmentam os conteúdos, mas estabelece entre eles relações cada vez maiores.

No caso das Histórias em Quadrinhos (HQs), outras contribuições são aferidas por E6, onde afirma que "[...] os quadrinhos enriquecem 0 vocabulário, pela utilização de palavras e ideias novas, por causa de assuntos variados, [...] e às vezes não percebemos este enriquecimento, pois acontece naturalmente" (E6). A justificativa desta naturalidade, indicado por E6, pode estar no fato deste recurso ser o mais próximo da realidade de todos que já foram crianças e jovens, na qual acabaram por transitar por estas leituras em algum momento de suas vidas. Os gibis foram os grandes amigos de muitas crianças, que passavam horas debruçadas nas crônicas da turma da Mônica, deixando suas imaginações tomarem conta de um universo cheio de aventura e diversão.

A indicação da ampliação do vocabulário, assim como os poemas, é proveniente das características dos gêneros textuais. Afinal, o vocabulário de um indivíduo é constituído pelas diferentes palavras adquiridas ao longo de suas leituras (VERGUEIRO, 2009). Enquanto um recurso as palavras podem ser rebuscadas exigindo maior interpretação, no outro recurso, a linguagem é mais acessível e encanta com suas imagens e cores.

Indiferente a especificidade do recurso, os entrevistados indicam a constituição de um novo vocabulário, com implicações diretas na melhoria da escrita, que se dá no momento da produção textual. Este fato fica evidente na fala de E8, ao afirmar que "[...] algumas habilidades de escrita são reforçadas, pois a partir do momento em que você começar a ter contato com estas leituras, começa a escrever melhor" (E8). Deste modo, as habilidades de leitura e escrita caminham juntas, ou seja, os indivíduos que 
leem, conhecem a gramática das palavras, as pontuações e a amplitude de vocabulário.

A elaboração de alguns recursos didáticos, como as Histórias em Quadrinhos, possibilita aperfeiçoar outra habilidade, como a síntese de textos. Na visão de E2 "[...] a confecção do material pode estimular esta habilidade, pois estimula as sínteses de mensagens, pela necessidade de apresentar as informações em pequenos espaços" (E2). A habilidade levantada pelo entrevistado remete àquelas atribuídas quando o indivíduo elabora suas próprias HQs. Isto ocorre devido à estrutura estabelecida pelos quadrinhos, nas quais limita o tamanho dos textos. Por conta da necessidade de sintetizar ideias, ao ter que colocar o texto em forma de narração e/ou fala dos personagens, dentro de cada balão. Neste sentido, para expor a mensagem, é necessário saber elaborar um texto sucinto e coerente. Assim, criar suas próprias HQs, segundo Luyten (1989), pode ser um método capaz de aprimorar o ato de escrever e síntese de ideias.

Outra contribuição apontada pelos entrevistados indica que os livros de divulgação científica despertam o interesse para conhecer novos materiais com tais características. Este fato ficou evidente na fala de E5 "[...] a partir do livro TIO TUNGSTÊNIO utilizado no PIBID comecei a ver que havia vários livros de Literatura nesta perspectiva e fui atrás de outros para conhecer, e encontrei o livro A colher que desaparece" (E5). Segundo Bastos (2008), este processo formativo corrobora para que o futuro professor construa um repertório de textos e de livros capazes de serem utilizados nas aulas de Química.

Os recursos didáticos como os jornais são gêneros textuais capazes de gerar ações contextualizadas nas aulas de Química. Na opinião de E8, "[...] as especificidades do recurso, devido ao caráter imediato e atual das notícias, pode ser uma vantagem para tratar de conteúdos científicos no contexto atual". Com isso, a utilização do jornal na prática dos professores de Química, por ter uma linguagem mais acessível com assuntos recentes e atualizados, revela-se uma atraente possibilidade para desenvolver ações contextualizadas nas aulas de Química. 
A potencialidade do recurso também está ao encontro de aguçar a sua criticidade pelo fato de "[...] precisar tomar cuidado com a veracidade das informações disponíveis naquela reportagem, pois na maioria das vezes os textos são escritos por leigos" (E5). O fato de ser leigo implica em dizer que - autor responsável por uma reportagem nem sempre tem formação específica para tratar de tal assunto. Isto significa que, nem sempre, as pessoas que escrevem sobre polvição nos rios, conhecem sobre ecossistema, resíduos químicos, leis ambientais etc. Neste sentido, levar este recurso para a sala de aula perpassa os conteúdos científicos possíveis de serem trabalhados, sendo assim, analisadas também, criticamente, as informações que ali são divulgadas.

De forma geral, o uso de tais gêneros textuais no processo formativo de professores proporciona que eles criem hábitos de leituras que não se limitem aos livros universitários. Apesar destas habilidades serem construídas ao longo do tempo, as poucas ações, como a realizada no âmbito do PIBID, já apresentam seus resultados. Um exemplo está na fala de R3, onde assume que "[...] ter contato com estes diferentes textos e Literatura, trouxe-Ihe o hábito de leitura" (R3). Neste pequeno trecho, fica evidenciado que este hábito foi instigado pelo fato de o sujeito conhecer as diferentes possibilidades de leituras e tornar-se um leitor mais assíduo.

Os gêneros textuais também possibilitam aos professores de Ciências/Química a trabalharem as questões de ortografia, mesmo que de forma indireta. Nas atividades "[...] o professor de Química, ao fazer uso de um texto, mesmo com suas prioridades nos conteúdos químicos, pode atentar-se a outras coisas, como pontuação, concordância e acentuação das palavras" (R5). Afinal, as questões de ortografia não precisam ser restringidas somente aos professores de Língua Portuguesa, mas as demais áreas do conhecimento, como as Ciências Exatas. Nota-se que a maioria das metodologias nas aulas de Química ainda se baseiam na memorização de conceitos químicos e reprodução de conceitos matemáticos, por se tratar de um campo potencialmente quantitativo, mas é indispensável levar em consideração as habilidades qualitativas (QUEIROZ, 2001). 
Atualmente, poucos estudantes formados nos cursos de Licenciaturas de Química têm a facilidade em redigir um texto de forma coerente, bem como expressar seus argumentos e escrever propostas didáticas (TEIXEIRA; SILVA, 2007). Sendo estas habilidades condições necessárias para realizar a análise crítica dos textos, como os materiais pedagógicos, redigir projetos de ensino nas escolas e apropriar-se de argumentos mais contundentes sobre a área de atuação. Tais competências são imprescindíveis tendo em vista que - professor deverá ser o futuro mediador tanto na construção de conhecimentos, quanto na apreciação do ato de ler. Portanto, ser professor de Química está além da apropriação dos conhecimentos científicos da área, é preciso também ser leitor capaz de despertar o prazer da leitura em todos os alunos.

A inexistência de práticas escolares com as inter-relações entre a Química com diferentes gêneros textuais ocorre devido ao desconhecimento dos professores das potencialidades didáticas de tais recursos, na qual acarreta o preconceito ao uso do material em sala de aula. Portanto, as práticas formativas como o espaço dentro do PIBID têm contribuído para os bolsistas familiarizarem-se com este recurso, sendo este momento, talvez, o primeiro contato com alguns deles. Sendo esta evidência indicada por E3, ao dizer: "Eu, como futura professora não conhecia as potencialidades dos poemas, das HQs, dos livros, [...] não tinha esta convicção antes de lidar com este material dentro das atividades do PIBID". Por isso, o contato, a manipulação e estudo dirigido dos recursos foram instrumentos favoráveis para adquirir o gosto e prazer por esta leitura, tornando-se consumidores destes produtos e apreciadores dos diversos gêneros textuais.

\section{CONSIDERAÇÕES FINAIS}

Os dados evidenciaram a existência de várias contribuições percebidas pelos bolsistas, conforme os seus apontamentos, para a melhoria da habilidade de leitura e escrita. Tais afirmações são indicadas pelos licenciandos que, durante um processo formativo, tiveram contato com 
diferentes gêneros textuais dentro do subprojeto de Química no PIBID. Para os entrevistados, quando os futuros professores têm contato com estes gêneros textuais, é possibilitado o enriquecimento do próprio vocabulário, sendo refletido na escrita destes sujeitos. Outra situação evidente aponta para o aperfeiçoamento de outra habilidade, como a interpretação de texto, e isto é indicado principalmente pelo uso dos poemas, visto que eles denotam maior compreensão do texto devido a sua composição versátil e rebuscada. A elaboração de alguns recursos didáticos, como é o caso das História em Quadrinhos (HQs) ainda promove o trabalho de síntese de texto, devido à necessidade de elaboração de textos sucintos e coerentes, para expressar a mensagem dos personagens em balões tão pequenos.

Todo este processo incentivou os futuros professores de Química a buscarem novos hábitos de leitura e a aguçarem a curiosidade de conhecer outros materiais com a mesma característica. Nesta perspectiva, o professor de Química consegue romper com a visão equivocada de que trabalhar as questões da leitura e escrita são unicamente responsabilidade dos professores de Língua Portuguesa. Qualquer professor, antes de tudo, precisa ser apreciador da leitura para estimular novos leitores na nossa sociedade.

Desta forma, acredita-se que o espaço de formação no âmbito do PIBID promoveu, aos futuros professores de Química, momentos de discussões que apresentaram novas estratégias de ensino por meio dos recursos didáticos, como é o caso dos diferentes gêneros textuais, a fim de que eles reconheçam a relevância de uma formação integral, que não priorize somente as habilidades quantitativas e conceituais da área de Química.

\section{REFERÊNCIAS}

ALMEIDA, M. J. P. M. Linguagens, leituras e ensino da ciência. Campinas: Mercado das Letras, 1998.

BALTAR, M. Letramentos e gêneros textuais midiáticos-escolares. Revista do Programa de Pós-graduação em Letras, Santa Maria, v. 20, n. 40, p. 177-190, 2010.

BARDIN, L. Análise de conteúdo. Lisboa: Edições 70, 2011.

BASTOS, T. Projeto versos coloridos - onde está a Poesia? In: Concurso Pontos de Leitura 2008 - Edição Machado de Assis, 2008, Caxias. Anais...Brasília: Ministério da Cultura, 2008, p. 1-9. 
BRASIL. Ministério da Educação. Base Nacional Curricular Comum (BNCC). Educação é a base, Brasília, 2017.

CAMARGO, F. P. A importância da poesia na formação de profissionais do ensino de literatura e sujeitos-leitores. Revista Poiésis, Niterói-RJ, v. 2, n. 2, 2004, p. 92-103.

CASSIANI, S.; NASCIMENTO, T.G. Um diálogo com as histórias de leituras de futuros professores de ciência. Pro-posições, Campinas v.17, 2006, p. 105-136.

COSTA, F. R. S.; CAMARGO, S.; SILVA, C. S. A mobilização de saberes a partir do uso de diferentes materiais didáticos no contexto do PIBID. ACTIO:

Docência em Ciências, Curitiba, v. 3, n. 1, 2018, p. 91-114.

COSTA, F. R. S.; SILVA, C. S.; CAMARGO, S. Análise de artigos publicados na Química Nova na Escola sobre o uso de materiais didáticos: foco na formação de professores. In: Encontro Nacional de Ensino de Química,18, 2016, Florianópolis. Anais...Florianópolis: Universidade Federal de Santa Catariana, 2016, p.1-12.

CUNHA, M. Literatura infantil: teoria e prática. 5ª ed. São Paulo: Ática, 1986.

DEYLLOT, M. E. C.; ZANETIC, J. Ler palavras, conceitos e mundo: o desafio de entrelaçar suas culturas. In: Encontro Nacional de Pesquisa em Ensino de Física, 9, 2004, Jaboticatubas. Anais... São Paulo; Sociedade Brasileira de Física, 2004, p.1-15.

DIONÍSIO, M. L. T.; PEREIRA, M. C. M. E.; VISEU, F. A. V. A leitura e a escrita no

currículo: a presença ausente. Atos de Pesquisa em Educação, Blumenau, $v$. 6, n.2, p. 94-114, jan./abr., 2011.

FLÔR, C.C. Na busca de ler para ser em aulas de Química. ljuí: Editora Unijuí, 2015.

FRANCISCO JUNIOR, W. E. Estratégias de leitura e Educação Química: que relações. Química Nova na Escola, São Paulo, v. 32, n. 4, 2010, p.220-226. FREIRE, P. A importância do ato de ler: em três artigos que se completam. 42.ed. São Paulo: Cortez, 2001.

GALVÃO, C. Ciência na literatura e literatura na ciência. Interacções, n. 3, 2006, p. 32-51.

LÜDKE, M.; ANDRÉ, M. E. D. Pesquisa em educação: abordagens qualitativas. São Paulo: EPU, 1986.

LUYTEN, S.M.B. História em Quadrinhos - Leitura crítica. 3. ed. São Paulo: Editora Paulinas, 1989.

MASSI, L.; SANTOS, G.R.; QUEIROZ, S.L. Artigos científicos no ensino superior de Ciências: ênfase no ensino de Química. Revista Electrónica de Enseñanza de las Ciencias, v.17, 2008, p.157-177.

NICHIO, E. R.; PACÍFICO, J. M. A prática da leitura literária: reflexão-açãotransformação por meio de grupo de diálogo coletivo. Revista Exitus, Santarém, v. 10, p. 01-30, 2020.

OLIVEIRA, C.M.; CARVALHO, A.M.P. Escrevendo em aulas de Ciências.

Ciência e Educação, Bauru, v.11,2005 p.347-366. 
PETIT, M. A arte de ler ou como resistir à adversidade. São Paulo: Ed. 34, 2008.

QUEIROZ, S.L. A linguagem escrita nos cursos de graduação em Química.

Química Nova, São Paulo, v. 24, n. 1, 2001, p. 143-146.

SCHEID, N.G. A poesia no espaço escolar: desafios e contribuições do gênero na formação de leitores. In: Jornada Nacional de Literatura Leituras Jovens do Mundo, 15, Passo Fundos. Anais...Passos Fundos: Portal da linguagem UPF, 2013, p.1-9.

SILVA, C. S. Poesia de António Gedeão e a Formação de professores de Química. Química Nova na Escola, São Paulo, v. 33, n. 2, 2011, p. 77-84.

SILVEIRA, M. P. Literatura e Ciência: Monteiro Lobato e o ensino de química. 2013. 297f. Tese (Doutorado em Ensino de Ciências) - Universidade de São Paulo, São Paulo, 2013.

SILVEIRA, M. P.; ZANETIC, J. Monteiro Lobato e Paulo Freire: problematizando o poço do Visconde. Química Nova na Escola, São Paulo, v. 39, n. 1, p. 89-03, 2017.

STRACK, R.; LOGUERCIO, R. de Q.; DEL PINO, J. C. Linguagem e interpretações de professores universitários sobre literatura de divulgação científica. In: Encontro Nacional de Pesquisa em Educação em Ciências, 6, Florianópolis. Anais.... Florianópolis: ABRAPEC, 2007, p.1-9.

TEIXEIRA JÚNIOR, J.G.; SILVA, R.M.G. Perfil de leitores em um curso de Licenciatura em Química. Química Nova na Escola, São Paulo, v. 30, n.5, 2007, p. 1365-1368.

VERGUEIRO, W. C. S.; RAMOS, P. E. (Orgs.). Quadrinhos na educação: da rejeição à prática. São Paulo: Contexto, 2009.

VOSGERAU, D.S.R.; PINHEIRO, R.B. O uso do jornal impresso na educação básica: resultados de uma década de pesquisa no Brasil. Revista Ibeoamericana de Educación, Espanha, n.59, 2012, p. 259-276.

ZANON, D. A. V.; ALMEIDA, M. J. P. M.; QUEIROZ, S. L. Contribuições da leitura de um texto de Bruno Latour e Steve Woolgar para a formação de estudantes em um curso superior de química. Revista Electrónica de Enseñanza de las Ciencias, Espanha, v. 6, n. 1, 2007, p. 56-69.

ZANOTTO, R. L.; STADLER, R. C. L.; CARLETTO, M. R. A utilização de Haicais como estratégias para o Ensino de Química. In: Simpósio Nacional de Ensino de Ciências e Tecnologia, 3, 2012, Ponta Grossa. Anais...Ponta Grossa: SINECT, 2012, p.1-9.

Recebido em: 11 de janeiro de 2021.

Aprovado em: 12 de maio de 2021. Publicado em: 04 de junho de 2021. 